\title{
Influence of Subinhibitory Concentrations of Cefotaxime, Imipenem and Ciprofloxacin on Adhesion of Escherichia coli Strains to Polystyrene
}

\author{
PATRYCJA ZALAS-WIĘCEK ${ }^{1 *}$, EUGENIA GOSPODAREK ${ }^{1}$ and KATARZYNA PIECYK² \\ ${ }^{1}$ Department of Clinical Microbiology, Nicolaus Copernicus University in Toruń \\ Ludwik Rydygier Collegium Medicum in Bydgoszcz, Poland \\ ${ }^{2}$ Department of Theoretical Foundations of Biomedical Sciences \& Medical Informatics, \\ Nicolaus Copernicus University in Toruń Ludwik Rydygier Collegium Medicum in Bydgoszcz, Poland
}

Received 11 May 2011, revised 10 August 2011, accepted 20 August 2011

Abstract

The present study investigated the ability of sub MICs of cefotaxime, imipenem and ciprofloxacin to interfere with adhesion of E. coli strains to polystyrene (selected polymer used in studies on microorganisms' adhesion). It was observed that cefotaxime and imipenem at $1 / 2$ and $1 / 4$ MICs decreased the adherence of $E$. coli strains to polystyrene significantly. $1 / 2,1 / 4$ and $1 / 8$ MICs of ciprofloxacin generally decreased the adhesive properties of E. coli strains, but two E. coli strains showed a noticeable enhancement of adhesion after incubation at sub MICs of this antibiotic.

Key words: Escherichia coli, adhesion to polystyrene, subinhibitory concentrations of antibiotics

Microorganisms regulate the expression of genes depending on signals coming from the environment they live in. Among them, these are: temperature, osmolarity, $\mathrm{O}_{2}, \mathrm{CO}_{2}, \mathrm{pH}$, nitrogen compounds, nutrient availability, inorganic ion concentrations and the presence of some specific substances in the environment (Guiney, 1997). Conditions prevailing in the environment have a significant influence on the process of the adhesion of microorganisms (Habash and Reid, 1999).

It has been accepted that eradication of microorganisms is possible to achieve, if between subsequent doses of the medicine (for about half of the time) the concentration of the antibiotic is higher than the value of the minimal concentration (MIC) inhibiting their growth. However, during infection treatment microorganisms are often subjected to influence of the antibiotic in concentration lower than the MIC (Braga et al., 2000, Davies et al., 2006).

Subinhibitory antibiotic concentrations (sub MICs) are not able to inhibit the growth but they can modify physicochemical properties of bacterial cells, affecting, e.g., their adhesion ability (Braga et al., 2000; Wojnicz et al., 2007; Shen et al., 2008). Sub MICs of antimicrobials can influence adhesion of bacteria by suppress- ing the synthesis and expression of specific adhesins, change of their structure and distribution, change of hydrophobicity and bacterium shape alteration. This can cause the loss of the ability of the microorganism to associate with receptors appearing on host cells (Vidya et al., 2005), as well as with abiotic surfaces.

The knowledge of sub MICs antibiotics influence on microorganisms is significant, particularly in the case of antimicrobial agents, whose penetration to tissues and organs is limited (Wojnicz, 2007).

As E. coli strains can cause medical-device associated infections and are able to survive in the hospital environment, the aim of this study was the evaluation of adhesion of these bacteria to polystyrene after incubation in the presence of sub MICs of cefotaxime, imipenem and ciprofloxacin - antibiotics commonly used in E. coli infection therapy.

This study included 74 E. coli strains isolated from urine and blood samples from patients hospitalized in the Clinical Microbiology Department of Dr A. Jurasz University Hospital, Poland between 2003 and 2006. Strains isolated from the same patient were not included in the study. All strains were stored at $-70^{\circ} \mathrm{C}$ in Brain Heart Infusion (BHI) medium (Becton Dickinson).

* Corresponding author: P. Zalas-Więcek, Department of Clinical Microbiology, Nicolaus Copernicus University in Toruń, Ludwik Rydygier Collegium Medicum in Bydgoszcz; 9M. Skłodowska-Curie Street, 85-094 Bydgoszcz, Poland; phone: (+48) 52 5853501; fax: (+48) 52 5854047; e-mail: patrycjazalas@go2.pl 
Antimicrobial agents used in this study were cefotaxime (MIP Pharma), imipenem (Merck Sharp and Dohme) and ciprofloxacin (KRKA). Antibiotics were stored according to the manufacturer's instructions and prepared fresh daily.

The MIC values for cefotaxime, imipenem and ciprofloxacin were determined with Etest (AB Biodisk). Each drug was tested at one-half, one-fourth and oneeighth of the MIC to study its effect on adhesion of E. coli strains. $256 \mu \mathrm{g} / \mathrm{ml}$ and $32 \mu \mathrm{g} / \mathrm{ml}$ were accepted respectively as the initial sub MICs value for E. coli strains which had the MIC cefotaxime value $>256 \mu \mathrm{g} / \mathrm{ml}$ and/or the MIC ciprofloxacin value $>32 \mu \mathrm{g} / \mathrm{ml}$.

Quantitation of E. coli adhesion to polystyrene was performed using the method described by Christensen et al. (Christensen et al., 1985) with some modifications (Stepanović et al., 2000).

The E. coli strains were incubated in $\mathrm{BHI}$ at $37^{\circ} \mathrm{C}$ for $20 \mathrm{~h}$. The cultures were centrifuged $(4,500 \mathrm{~g} / 10 \mathrm{~min})$ and then rinsed twice in sterile 0,01 M PBS, pH 7,2. Thus obtained sediment was diluted with sterile Mueller Hinton Broth, MHB (Becton Dickinson) including an antibiotic so that to obtain the inoculum of 0,5 according to McFarland scale and final concentration of the MICs solution $1 / 2,1 / 4$ and $1 / 8$, respectively. One hundred fifty microlitres of this inoculum was added to the wells of sterile 96 -well polystyrene microtiter plates (Medlab). The results were observed after overnight incubation at $37^{\circ} \mathrm{C}$.

The strains were incubated for $20 \mathrm{~h}$ at $37^{\circ} \mathrm{C}$. Afterwards the supernatant from each well was gently aspired with a micropipette and microtiter plates were rinsed three times with sterile PBS, $\mathrm{pH} 7.2$ to remove nonadherent bacteria for bacterial quantification. The remaining attached bacteria were fixed with $96 \%$ ethanol (Polskie Odczynniki Chemiczne, POCh) for $1 \mathrm{~min}$ at room temperature, and then stained with crystal violet for $5 \mathrm{~min}$. After washing in tap water to remove excess stain, the plates were air-dried in an inverted position. The optical density (OD) of each well was measured at $570 \mathrm{~nm}$ by using a microtiter plate reader Synergy HT (BIO-TEK).

Sterile MHB medium was used as a negative control. The experiment was carried out in triplicate. The results were averaged. Adhesion classification was extended to four categories (lack of adhesion, weak adhesion, medium adhesion, strong adhesion).

In order to determine the existence of differences between two variables the test of two rates of structure (Stanisz, 2001; Krysicki et al., 2002) was used. The differences were considered to be statistically significant for $\alpha=0,05$.

E. coli strains incubated at $1 / 2$ and $1 / 4$ of cefotaxime MICs significantly more rarely (in both cases $\mathrm{p}=0.048$ ) adhered to polystyrene than strains incubated in the

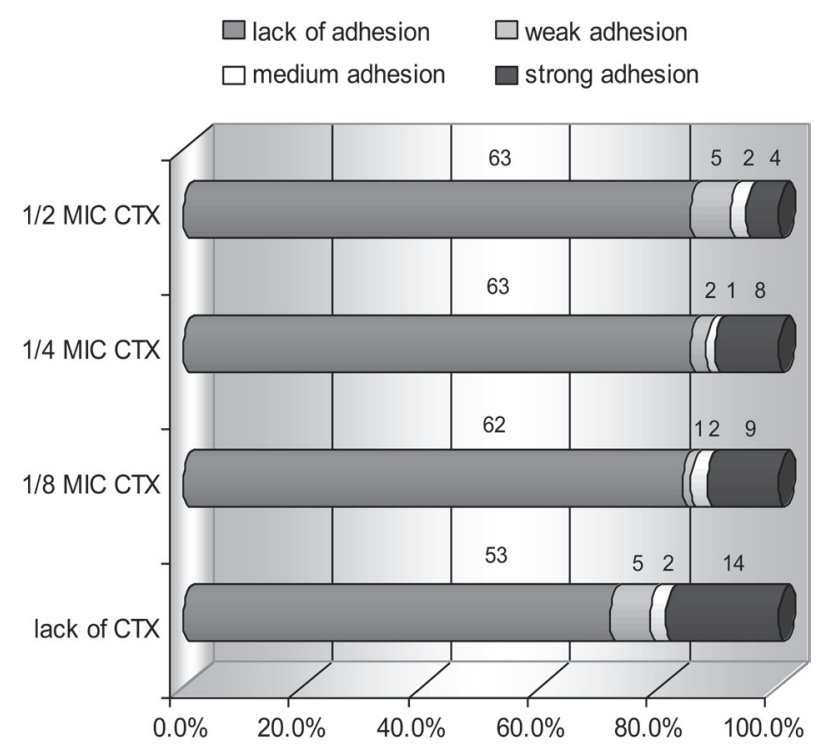

Fig. 1. Degree of adhesion to polystyrene of E. coli strains $(\mathrm{n}=74)$ at subinhibitory concentrations of cefotaxime (CTX)

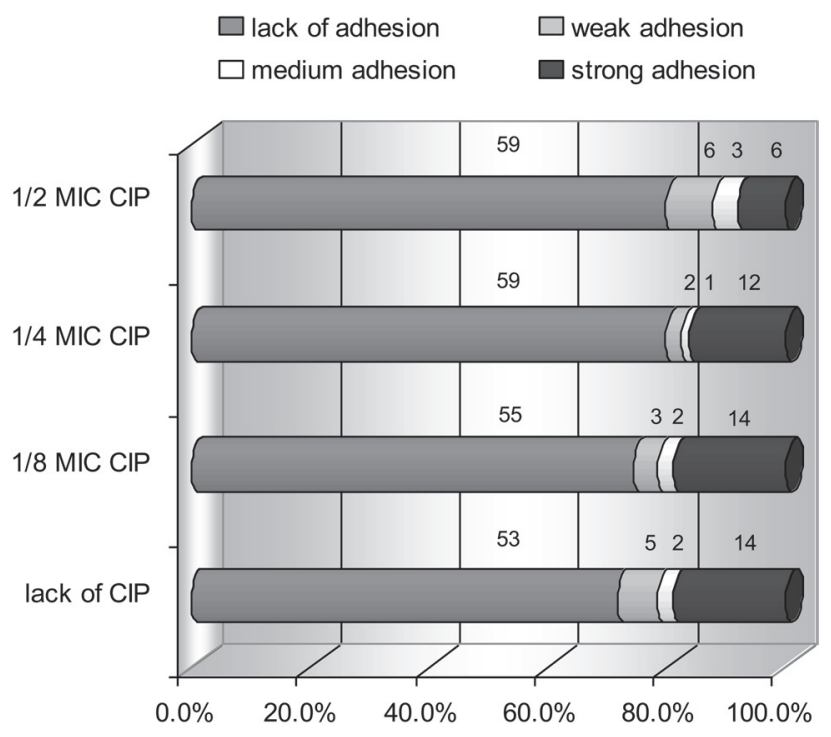

Fig. 2. Degree of adhesion to polystyrene of E. coli strains $(\mathrm{n}=74)$ at subinhibitory concentrations of imipenem (IPM)

medium without this antibiotic (Fig. 1). Examined E. coli strains significantly more often adhered strongly to polystyrene during incubation in MHB medium without the addition of the antibiotic than after incubation at $1 / 2$ cefotaxime MIC $(p=0,010)$ (Fig. 1).

A characteristically smaller frequency of the adhesion to polystyrene was determined among strains incubated at $1 / 2$ and $1 / 4$ of imipenem MICs (in both cases $p=0.048$ ) than after incubation in MHB medium without this carbapenem (Fig. 2). Examined strains revealed a significantly smaller frequency of the strong adhesion at $1 / 2$ of imipenem MIC than after incubation in MHB medium and in this medium with at $1 / 4$ and $1 / 8$ of imipenem MICs (the $p$ values were, $0.005,0.030$ and 0.017 , respectively). 


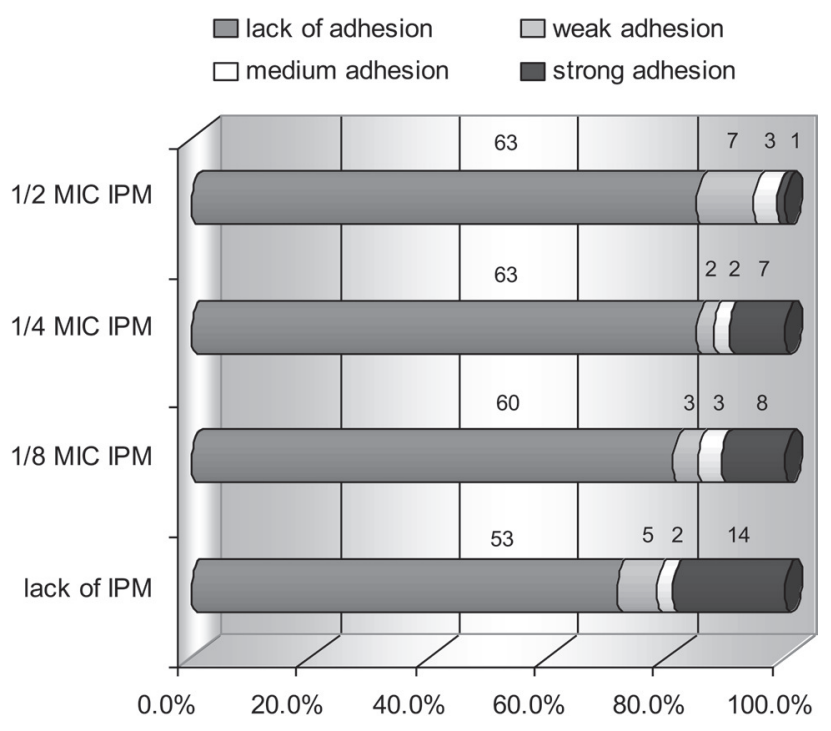

Fig. 3. Degree of adhesion to polystyrene of E. coli strains $(\mathrm{n}=74)$ at subinhibitory concentrations of ciprofloxacin (CIP)

E. coli strains incubated at $1 / 2,1 / 4$ and $1 / 8$ of ciprofloxacin MICs adhered in lower (with the exception of two strains) percentage to polystyrene, in comparison with strains incubated in MHB medium without this antibiotic. Higher percentages of strains with strong adhesion were revealed amongst strains incubated in MHB medium and at $1 / 4$ and $1 / 8$ of ciprofloxacin MICs than amongst strains incubated in MHB medium with the addition of $1 / 2$ of ciprofloxacin MIC (Fig. 3). Ciprofloxacin sub MICs increased adherence of two E. coli strains to this polymer.

Analyzing the pharmacokinetics of antimicrobial agents it is possible to notice, that after dosing, their concentration above the MIC value is maintained only for a defined period of time, and then it falls to the level below this value, achieving subinhibitory concentrations.

Sub MICs of antimicrobial agents can appear between single doses of antibiotic, after last dose of antibiotic and in tissues involved in sickness process, in which the concentration of the antibiotic is often lower than in blood (Braga et al., 1995). Since antibiotics at sub MIC concentrations can influence adhesion properties of the bacteria and their ability to biofilm formation (Braga et al., 2000), this study was an attempt to estimate the impact of three chosen antibiotics, belonging to separate therapeutic groups, applied in treatment of infections by E. coli strains, on the adhesion of these bacteria to the polystyrene was taken.

In our examinations a significantly smaller frequency of the adhesion of E. coli strains to polystyrene after the incubation at $1 / 2$ and $1 / 4$ of cefotaxime and imipenem MICs was stated than after the incubation in MHB medium without these antibiotics. In both cases the lowest frequency of the adhesion of E. coli strains to polystyrene was observed at $1 / 2$ of antibiotics MICs. Braga et al. (Braga et al., 1997) examined the influence of sub MICs of cefodizime, cefotaxime and ceftriaxone at concentrations ranging from $1 / 2$ do $1 / 128$ MICs on the morphology and the adhesion of E. coli strains to human buccal epithelial cells. Inhibition of the adhesion of E. coli strains to epithelial cells was being observed in cases, where cephalosporins concentration was $1 / 2$ to $1 / 64$ MICs, whereas cephalosporins in the $1 / 2$ MIC concentration suppressed adhesion to the highest extent. Incubation of $E$. coli strains at $1 / 2,1 / 4$ and $1 / 8$ of cefodizime MICs caused the loss of adhesion abilities in about $90 \%$ of bacteria and correlated with fimbria disappearance. Hence, the authors supposed that fimbria loss on the surface of bacterial cells could be a result of cell wall synthesis disorders caused by the cephalosporin and so it influenced adhesion properties of E. coli strains. Using an electron microscope the authors noticed that sub MICs of cephalosporins influenced a change in the morphology of $E$. coli rods. The filamentation of E. coli cells was mainly observed, but along with round filaments there were often interrupted or flattened filaments, a result of the escape of cytoplasmic content, making the bacterial cells resemble so-called 'cell shadows'. Other morphological changes observed in E. coli included a few random spheroplast-like structures and the formation of bulges in the middle of the filament.

Zwierzchlewski (Zwierzchlewski, 2003) observed decrease in adhesion to polystyrene and paraxylene in Acinetobacter spp. rods after incubation at imipenem sub MICs. The frequency of adhesion depended on carbapenem concentration and the higher carbapenem concentration was the lower adhesion frequency. Vidal et al. (Vidal et al., 1997) observed generation of big, oval cells of A.baumannii in an electron microscope after incubation at imipenem sub MICs what correlated with the drop in adhesion to glass surfaces.

In the presented study the E. coli strains incubation at sub MICs of cefotaxime and imipenem could cause disturbances in synthesis of cellular wall, and hence the expression on its surface of the elements responsible for adhesion. It is not excluded, that there was change in the shape of E. coli cells, what could influence their adhesion to polystyrene.

The aim of this study was also the assessment of the impact of ciprofloxacin sub MICs on adhesion of E. coli to polystyrene. E. coli strains incubated in all accepted sub MICs concentrations of ciprofloxacin usually adhered in the lower percentage to polystyrene, in comparison to strains incubated in medium without the presence of this antibiotic agent. After the incubation at $1 / 4$ and $1 / 8$ of ciprofloxacin MICs, a higher percentage of strains was observed at $1 / 2$ MIC demonstrating strong adhesion. 
Vidya et al. (Vidya et al., 2005) observed that ciprofloxacin sub MICs caused filamentation of E. coli cells, what correlated with drop in adhesion of these rods to human vaginal epithelial cells. Other authors (Drago et al., 2001) claimed that incubation of E. coli rods at ciprofloxacin and levofloxacin sub MICs causes the decrease in the adhesion of these bacteria to the uroepithelial cells.

Additionally, loss of haemagglutination ability as a result of influence of quinolone antibiotics sub MICs was also described as regards E. coli strains (Baskin et al., 2002). Moreover, a relation between the concentration of quinolone antibiotics and their influence on decreased adhesion of these bacteria was proved (Drago et al., 2001; Vidya et al., 2005). The higher sub MICs of quinolone antibiotics the fewer E. coli rods had adhesive properties.

Di Bonaventura et al. (Di Bonaventura et al., 2004) investigated the in vitro effects of fluoroquinolones (ciprofloxacin, grepafloxacin, levofloxacin, moxifloxacin, norfloxacin, ofloxacin and rufloxacin), trimethoprim-sulfamethoxazole and ceftazidime on adhesion properties and biofilm formation of polystyrene surface of Stenotrophomonas maltophilia strains. All of fluoroquinolones at $1 / 2$ and $1 / 4$ of MICs (except for norfloxacin) reduced adhesion of S. maltophilia strains to polystyrene, and clinically achievable concentrations (50 and $100 \mu \mathrm{g} / \mathrm{ml}$ ) of rufloxacin were able to eradicate preformed S. maltophilia biofilm.

In two out of 74 analyzed E. coli strains sub MICs of ciprofloxacin were observed to enhance adhesion to polystyrene. A similar effect was also observed by Balagué et al. (Balagué et al., 2003) during examination of uropathogenic E. coli (UPEC) strains expressing mannose-resistant adhesions different from type P. In 13 out of 25 strains after incubation with ciprofloxacin at $1 / 4$ of MIC showed a noticeable enhancement of haemagglutination and/or surface hydrophobicity which correlated with a higher expression of surface proteins. UPEC strains with enhanced hydrophobicity increased their adhesiveness to urinary catheters. These results indicate that ciprofloxacin at low concentrations could increase the adhesiveness and hence the risk of colonization by UPEC strains expressing mannose-resistant adhesions different from type P. It is likely that two E. coli strains described in this work presented a similar phenotype. In the future this would need to be confirmed experimentally.

Disturbances of DNA replication, caused by quinolones, can have an indirect influence on the synthesis of proteins exposed on the cell surface which perform the role of adhesins or give the cell hydrophobic properties.

Own research results and results obtained by other authors undoubtedly prove antibiotics at sub MICs concentrations can inhibit, though to a various extent, bacterial adhesion to polymers. It can be presumed that studied in vitro suppressing the bacterial cells' adhesion ability can occur also in vivo.

In the light of these results, it is possible to seek a chance to create effective strategies of prevention against biomaterials' colonization by bacteria and hence inhibiting of the first stage of infection. However, one should not ignore the opinion that sub MICs of antibiotics agents could sometimes contribute to selection of resistant strains. If this direction of research can turn out to be risky then at least the knowledge about the influence of antibiotics sub MICs on microorganisms in connection with their acquaintance of their pharmacokinetics could turn out to be useful in establishing rational antibacterial therapy.

\section{Acknowledgements}

This research was funded by Nicolaus Copernicus University in Toruń, SD grant no. 62/04.

\section{Literature}

Balagué C., L. Fernández, J. Pérez and R. Grau. 2003. Effect of ciprofloxacin on adhesive properties of non-P mannose-resistant uropathogenic Escherichia coli isolates. J. Antimicrob. Chemother. 51: 401-404.

Baskin H., Y. Doğan, I.H. Bahar and N. Yuluğ. 2002. Effect of subminimal inhibitory concentrations of three fluoroquinolones on adherence of uropathogenic strains of Escherichia coli. Int. J. Antimicrob. Agents. 19: 79-82.

Braga P.C., M. Dal Sasso and S. Maci. 1997. Cefodizime: effects of sub-inhibitory concentrations on adhesiveness and bacterial morphology of Staphylococcus aureus and Escherichia coli: comparison with cefotaxime and ceftriaxone. J. Antimicrob. Chemother. 39: 79-84.

Braga P.C., M. Dal Sasso, S. Maci, S. Reggio and G. Piatti. 1995. Influence of subinhibitory concentrations of brodimoprim and trimethoprim on the adhesiveness, hydrophobicity, hemagglutination and motility of Escherichia coli. Chemotherapy. 41: 50-58.

Braga P.C., M. Dal Sasso and M.T. Sala. 2000. Sub-MIC concentrations of cefodizime interfere with various factors affecting bacterial virulence. J. Antimicrob. Chemother. 45: 15-25.

Christensen G.D., W.A. Simpson, J.J. Younger, L.M. Baddour, F.F. Barrett, D.M. Melton and E.H. Beachey. 1985. Adherence of coagulase-negative staphylococci to plastic tissue culture plates a quantitative model for adherence of staphylococci to medical devices. J. Clin. Microbiol. 22: 996-1006.

Davies J., G.B. Spiegelman and G. Yim. 2006. The world of subinhibitory antibiotic concentrations. Curr. Opin. Microbiol. 9: 445-453.

Di Bonaventura G., I. Spedicato, D. D’Antonio, I. Robuffo and R. Piccolomini. 2004. Biofilm formation by Stenotrophomonas maltophilia: modulation by quinolones, trimethoprim-sulfamethoxazole and ceftazidime. Antimicrob. Agents Chemother. 48: 151-160. Drago L., E. De Vecchi, B. Mombelli, L. Nicola, M. Valli and M.R. Gismondo. 2001. Activity of levofloxacin and ciprofloxacin against urinary pathogens. J. Antymicrob. Chemother. 48: 37-45.

Guiney D.G. 1997. Regulation of bacterial virulence gene expression by the host environment. J. Clin. Invest. 99: 565-569. 
Habash M. and G. Reid. 1999. Microbial biofilms: their development and significance for medical device-related infections. J. Clin Pharmacol. 39: 887-898.

Krysicki W., J. Bartos, W. Dyczka, K. Królikowska and M. Wasilewska. 2002. Rachunek prawdopodobieństwa i statystyka matematyczna $w$ zadaniach cz. II. Statystyka matematyczna. Warszawa: PWN.

Shen L., Y. Shi, D. Zhang, J. Wei, M.G. Surette and K. Duan. 2008 Modulation of secreted virulence factor genes by subinhibitory concentrations of antibiotics in Pseudomonas aeruginosa. J. Microbiol 46: 441-447.

Stanisz A. 2001. Przystępny kurs statystyki w oparciu o program STATISTICA PL na przykładach $z$ medycyny. Kraków: StatSoft Polska. Stepanovic S., D. Vukovic, I. Dakic, B. Savic and M. SvabicVlahovic. 2000. A modified microtiter-plate test for quantification of staphylococcal biofilm formation. J. Microbiol. Methods 40:175-9.
Vidal R., M. Dominguez, H. Urrutia, H. Bello, A. Garcia, G. Gonzalez and R. Zemelman. 1997. Effect of imipenem and sulbactam on sessile cells of Acinetobacter baumannii growing in biofilm. Microbios. 91: 79-87.

Vidya K.C., P.S. Mallya and P.S. Rao. 2005. Inhibition of bacterial adhesion by subinhibitory concentrations of antibiotics. Indian. J. Med. Microbiol. 23: 102-105.

Wojnicz D. 2007. Wpływ stężeń podprogowych antybiotyków na zdolności adhezyjne bakterii. Adv. Clin. Exp. Med. 16: 141-148.

Wojnicz D, Kłak M, Adamski R, Jankowski S. 2007. Influence of subinhibitory concentrations of amikacin and ciprofloxacin on morphology and adherence ability of uropathogenic strains. Folia Microbiol. 52: 429-436.

Zwierzchlewski T. 2003. Wpływ wybranych czynników na adhezję pałeczek Acinetobacter spp. do polimerów. Akademia Medyczna im. L. Rydygiera Bydgoszcz; rozprawa doktorska. 